\title{
Penjatuhan Sanksi Pidana Dalam Kasus Penambangan Batu Cinnabar di Maluku*
}

\author{
Erwin Ubwarin ${ }^{1}$, Wilshen Leatemia ${ }^{2}$ \\ Program Studi Ilmu Hukum, Fakultas Hukum Universitas Pattimura \\ doi) https://doi.org/10.32507/mizan.v4i2.841
}

\begin{abstract}
All natural resource wealth in the land, sea, and in the bowels of the land of Indonesia are controlled by the State and used as much as possible for the welfare of the people. However, the processing of cinnabar stone natural resources that does not queue up the permit in Luhu Village, West Seram Regency, Maluku Province has resulted in environmental pollution and has an impact on humans. Overcoming this criminal violation, law enforcement has been carried out which resulted in 8 (eight) decisions at the Ambon District Court. This research was conducted with a juridical normative approach, with a statutory approach and a conceptual approach to the imposition of crimes and criminal acts that place statutory regulations as objects of research sourced from primary, secondary and tertiary law. The results of the research conclude that criminal charges against miners without a permit are still low, less than half of the maximum threat of 10 (ten) years in the mineral and coal mining law, this is very unfortunate because the damage to the environment due to processing of cinnabar stone without permission will have a long impact.
\end{abstract}

Keywords: Criminal, Cinnabar, Mining

\begin{abstract}
Abstrak
Semua kekayaan sumber daya alam yang ada di darat, laut, dan di dalam perut bumi Indonesia dikuasai oleh Negara dan digunakan sebesarnya untuk kesejahteraan rakyat. Namun pengelolaan sumber daya alam batu cinnabar yang tidak mengantongi izin pada Desa Luhu Kabupaten Seram Barat, Provinsi Maluku berakibat pada pencemaran lingkungan dan berdampak pada manusia. Menanggulangi pelanggaran pidana ini telah dilakukan penegakan hukum yang menghasilkan 8 (delapan) putusan pada Pengadilan Negeri Ambon. Penelitian ini dilakukan dengan pendekatan yuridis normatif, dengan pendekatan peraturan perundang-undangan dan pendekatan konsep tentang penjatuhan pidana dan tindak pidana yang menempatkan peraturan perundang-undangan sebagai objek penelitian yang bersumber dari hukum primer, sekunder, dan tersier. Hasil penelitian menyimpulkan penjatuhan pidana kepada pelaku penambang tanpa izin masih rendah tidak sampai setengah dari ancaman maksimum 10 (sepuluh) tahun dalam undang-undang pertambangan mineral dan batu bara, hal ini sangat disayangkan karena rusaknya lingkungan akibat pengelolaan batu cinnabar tanpa izin akan berdampak panjang.
\end{abstract}

Kata Kunci: Pidana, Cinnabar, Pertambangan

* Naskah diterima tanggal: 15 September 2020, direvisi: 17 Oktober 2020, disetujui untuk terbit: 10 Desember 2020.

${ }^{1}$ Erwin Ubwarin adalah peneliti pada Fakultas Hukum Universitas Pattimura. Jalan Ir. M. Putuhena Kampus Unpatti Poka-Ambon. Kode Pos. 97233. e-mail: laman:fakhum_unpatti@yahoo.com. fhukum.unpatti.ac.id.

${ }^{2}$ Wilshen Leatemia adalah peneliti pada Fakultas Hukum Universitas Pattimura. Jalan Ir. M. Putuhena Kampus Unpatti Poka-Ambon. Kode Pos. 97233. e-mail: laman:fakhum_unpatti@yahoo.com. fhukum.unpatti.ac.id. 


\section{A. PENDAHULUAN}

Bangsa Indonesia memiliki berbagai macam kekayaan alam baik yang ada di laut dan di darat. Pemanfaatan dan pengelolaan kekayaan alam di Indonesia dilakukan oleh Pemerintah sesuai dengan Pasal 33 ayat (3) Undang-undang Dasar Negara Republik Indonesia Tahun 1945 (selanjutnya disingkat UUD 1945), yang menyebutkan bahwa "Bumi dan air serta kekayaan alam yang terkandung di dalamnya dikuasai oleh Negara dan dipergunakan untuk sebesar-besarnya bagi kemakmuran rakyat. Pengelolaan ini harus sesuai dengan pembangunan yang memperhatikan keberlanjutan sumber daya alam yang tidak dapat diperbaharui dan kesejahteraan penduduk lokal di sekitar daerah tambang.

Di Provinsi Maluku ada beberapa daerah tambang yang sementara dianalisis untuk dieksplorasi seperti Blok Marsela, ada yang sudah jalan proses pengelolaan sumber daya alamnya seperti lapangan minyak Kota Bula, Kabupaten Seram Bagian Timur. Lapangan minyak ini sudah ada dari era kolonial sampai pada era reformasi, dan sudah banyak perusahan yang mengambil alih pengeboran minyak mentah di Pulau Seram. Bukan saja minyak yang ada di Pulau Seram, namun pulau tersebut juga mempunyai salah satu potensi yaitu batu cinnabar.

Cinnabar merupakan salah satu bahan tambang yang banyak dicari oleh orang yang ingin mengkonversi batu cinnabar menjadi cairan merkuri. Merkuri di alam terdapat dalam bentuk mineral amalgam dengan aluminium, perak, seng, emas atau dalam bentuk cinnabar (HgS). ${ }^{3}$ Biji emas seringkali mengandung merkuri dengan kadar tinggi maupun rendah, karena merkuri dapat berasosiasi dengan bijih emas merkuri dapat menurunkan persentase rekoveri pada proses segmentasi maupun adsorpsi untuk memperoleh emas, sehingga merkuri harus dihilangkan atau diendapkan. Merkuri dapat lepas ke lingkungan dalam jumlah besar dikarenakan proses sianidasi emas yang dilakukan tanpa adanya tahapan penghilangan merkuri. ${ }^{4}$ Merkuri yang terlepas ke lingkungan dapat menyebabkan lingkungan terkontaminasi dan dapat merusak kesehatan. Untuk itulah penegakan hukum pidana tidak boleh main-main dengan para pelanggar pengelolaan batu cinnabar yang tidak mengantongi izin.

Pelaku pertambangan bisa dikelompokkan dengan pertambangan skala besar, pertambangan skala menengah dan juga pertambangan skala kecil dalam bentuk pertambangan rakyat. Kegiatan pertambangan banyak menimbulkan persoalan baik terhadap lingkungan maupun terhadap masyarakat setempat. Persoalan pertambangan tidak hanya ditimbulkan oleh pertambangan skala besar saja tetapi pertambangan skala menengah maupun pertambangan skala kecil. Pertambangan dalam skala kecil dilakukan dalam bentuk pertambangan rakyat. Dalam melakukan kegiatan pertambangan rakyat walaupun termasuk dalam pertambangan skala kecil tetapi bukan berarti tidak mempunyai persoalan. Meskipun diusahakan secara

\footnotetext{
${ }^{3}$ Rosita Rizki Maulidiah dan Suprapto, Pemisahan Merkuri dari Batuan Cinnabar dengan Asam dan Campuran Asam-Kalium Iodida, JURNAL SAINS DAN SENI ITS Vol. 4, No.2, hal 109

${ }^{4}$ Coles, C. A. (2006). Mercury Cyanide Contamination of Groundwater from Gold Mining and Prospects for Removal. Sea to Sky Geotechnique, hal. 1118-1122.
} 
tradisional, tetapi terkadang meliputi wilayah yang cukup luas, karena diusahakan oleh masyarakat setempat dengan pelaku usaha yang tidak diimbangi dengan peralatan, fasilitas, pengetahuan, dan permodalan. Di samping sebagai keterbatasan tadi, kendala aturan turut memperparah situasi dan kondisi, sehingga tambang rakyat cenderung dilakukan tanpa izin (PETI), sehingga rentan terhadap kecelakaan dan keselamatan kerja, dan terkadang menimbulkan pencemaran dan kerusakan lingkungan yang tidak terkendali. ${ }^{5}$

Pengelolaan mineral dan batubara di Indonesia didasarkan pada UndangUndang Nomor 4 Tahun 2009 tentang Pertambangan Mineral dan Batubara (selanjutnya disingkat Undang-Undang Minerba). Pengaturan hukum dalam UndangUndang Minerba mewajibkan kepada seseorang atau pihak yang akan melakukan kegiatan pertambangan (pelaku usaha) harus memiliki sejumlah izin, seperti Izin Usaha Pertambangan (IUP), Izin Pertambangan Rakyat (IPR) atau Izin Usaha Pertambangan Khusus (IUPK), sehingga bila sudah memiliki izin-izin sebagaimana dimaksud diatas, barulah dapat dilakukan kegiatan pertambangan. Tentunya izin digunakan sebagai instrumen hukum yang digunakan oleh Pemerintah untuk mengendalikan masyarakat. ${ }^{6}$

Pertambangan di Provinsi Maluku sudah ditetapkan oleh Menteri Energi Sumber Daya Mineral melakukan keputusan Mentri ESDM No. 367 K/30/MEM/2017 tentang Penetapan Wilayah Pertambangan Kepulauan Maluku dan daerah desa Iha /Luhu Kecamatan Haumual Kabupaten Seram Bagian Barat masuk dalam Wilayah Pencadangan Negara (WPN). Pertambangan mineral logam jenis cinnabar yang merupakan bahan utama penghasil merkuri/raksa di Desa Tha/Luhu Kecamatan Haumual Kab. Seram Bagian Barat belum ada izin, sehingga aktivitas pertambangan pada areal dimaksud merupakan kegiatan ilegal. Penggunaan hukum pidana untuk penanganan kegiatan ilegal ini telah dilakukan dengan Putusan Pengadilan Negeri Ambon yaitu:

\begin{tabular}{|c|c|c|}
\hline No & Nomor Perkara & \multicolumn{1}{|c|}{ Pidana Yang dijatuhkan } \\
\hline 1 & 47/Pid.Sus/2018/PN. Amb & 1 Tahun, dan Denda Rp. 500.000.000 \\
\hline 2 & 48/Pid.Sus/2018/PN. Amb & 8 Bulan dan Denda Rp. 500.000.000 \\
\hline 3 & 221/Pid.Sus/2018/PN Amb & 2 Tahun dan Denda Rp. 1.000.000.000 \\
\hline 4 & 241/Pid.Sus/2018/PN Amb & 1 Tahun 2 Bulan dan Denda Rp. 1.000.000 \\
\hline 5 & 242/Pid.Sus/2018/PN Amb & 8 Bulan dan Denda Rp. 1.000.000 \\
\hline 6 & 244/Pid.Sus/2018/PN Amb & 8 Bulan denda Rp. 1.000.000 \\
\hline 7 & 304/Pid.Sus/2018/PN Amb & 2 Tahun 6 Bulan dan Denda Rp.100.000.000 \\
\hline 8 & 187/Pid.Sus/2019/PN Amb & 4 Bulan dan Denda Rp. 500.000 \\
\hline
\end{tabular}

Tabel I Putusan Tindak Pidana Minerba Tahun 2018-2019

Sumber: Humas Pengadilan Negeri Ambon

${ }^{5}$ Nandang Sudrajat, Teori dan Praktik Pertambangan Indonesia Menurut Hukum, Pustaka Yustisia, Jakarta, 2010, hal. 76.

${ }^{6}$ Philipus M. Hadjon, Perlindungan Hukum Bagi Rakyat di Indonesia, Sebuah Studi tentang PrinsipPrinsipnya dan Penanganannya oleh Pengadilan Dalam Lingkungan Peradilan Umum dan Pembentukan Peradilan Administrasi, Edisi Khusus, Penerbit Peradaban, Cet. Pertama, 2007, hal 32. 
Dari tabel diatas menunjukan dalam tahun 2018-2019 terus terjadi penambangan liar yang tidak mengantongi izin, namun hukuman yang dijatuhkan sangat rendah tidak sampai seperdua dari ancaman pidana yang ada dalam Undang-Undang Nomor 4 Tahun 2009 tentang Mineral dan Batu Bara, maka penulis ingin membahas tentang penjatuhan pidana yang masih rendah hukumannya dalam perkara penambangan ilegal, sementara pada sisi lingkungan akan berbahaya bagi lingkungan dan masyarakat yang hidup dalam lingkungan tersebut.

\section{B. METODE PENELITIAN}

Penelitian terhadap putusan pengadilan, menggunakan pendekatan yuridisnormatif yang menempatkan peraturan perundang-undangan sebagai obyek penelitian. Penelitian yuridis-normatif disebut juga dengan istilah penelitian doktrinal yang meneliti sumber pustaka atau dokumen hukum sebagai obyek kajian atau sasaran penelitian. Sumber hukum primer peraturan perundang-undangan dan putusan pengadilan yang menjadi obyek penelitian adalah: (1) Undang-Undang Dasar Tahun 1945; (2) Undang-Undang Nomor 4 Tahun 2009 Tentang Pertambangan Mineral dan Batu Bara; (3) Keputusan Menteri ESDM No. 367 K/30/MEM/2017 tentang Penetapan Wilayah Pertambangan Kepulauan Maluku dan daerah desa Tha/Luhu Kecamatan Haumual Kabupaten Seram Bagian Barat masuk dalam wilayah Pencadangan Negara (WPN), dan (4) Putusan-putusan pengadilan yang berhubungan dengan pengelolaan ilegal batu cinnabar di Maluku

Dokumen hukum sekunder adalah hukum dalam bentuk buku-buku hukum dan buku-buku non-hukum yang berkaitan dengan penelitian ini maupun karya-karya tulis di bidang hukum yang dalam bentuk artikel yang terbit pada jurnal-jurnal hukum. Hukum sekunder berfungsi untuk menjelaskan terhadap bahan-bahan hukum primer. Sedangkan dokumen hukum tersier adalah hukum berbentuk kamus hukum, ensiklopedi hukum dan lain-lain. Dokumen hukum tersier ini merupakan bahan hukum yang memberikan petunjuk maupun penjelasan terhadap bahan hukum primer dan sekunder. Analisis data penelitian bersifat deskriptif-kualitatif untuk menjelaskan tentang penjatuhan pidana dan bagaimana mengontrol masyarakat dengan hukum pidana.

\section{ANALISIS DAN PEMBAHASAN}

\section{Sistem Pemidanaan di Indonesia}

Mengenai jenis pidana yang terdapat dalam sistem pemidanaan di Indonesia, terdapat dalam Pasal 10 KUHP, yang menyatakan pidana terdiri dari, a) pidana pokok yang termasuk di dalamnya yaitu pidana mati, pidana penjara, pidana kurungan, pidana denda, dan b) pidana tambahan yang termasuk di dalamnya yaitu pencabutan hak-hak tertentu, perampasan barang-barang tertentu, dan pengumuman putusan hakim. Untuk tindak pidana mineral dan batu bara ancaman pidana diatur dalam Bab XXIII, ada 8 (delapan) pasal yang mengatur tentang perbuatan yang diancam pidana. 
Pasal 158

Setiap orang yang melakukan usaha penambangan tanpa IUP, IPR atau IUPK sebagaimana dimaksud dalam Pasal 37, Pasal 40 ayat (3), Pasal 48, Pasal 67 ayat (1), Pasal 74 ayat (1) atau ayat (5) dipidana dengan pidana penjara paling lama 10 (sepuluh) tahun dan denda paling banyak Rp10.000.000.000,00 (sepuluh miliar rupiah).

Pasal 159

Pemegang IUP, IPR, atau IUPK yang dengan sengaja menyampaikan laporan sebagaimana dimaksud dalam Pasal 43 ayat (1), Pasal 70 huruf e, Pasal 81 ayat (1), Pasal 105 ayat (4), Pasal 110, atau Pasal 111 ayat (1) dengan tidak benar atau menyampaikan keterangan palsu dipidana dengan pidana penjara paling lama 10 (sepuluh) tahun dan denda paling banyak Rp10.000.000.000,00 (sepuluh miliar rupiah).

Pasal 160

(1) Setiap orang yang melakukan eksplorasi tanpa memiliki IUP atau IUPK sebagaimana dimaksud dalam Pasal 37 atau Pasal 74 ayat (1) dipidana dengan pidana kurungan paling lama 1 (satu) tahun atau denda paling banyak Rp200.000.000,00 (dua ratus juta rupiah).

(2) Setiap orang yang mempunyai IUP Eksplorasi tetapi melakukan kegiatan operasi produksi dipidana dengan pidana penjara paling lama 5 (lima) tahun dan denda paling banyak Rp10.000.000.000,00 (sepuluh miliar rupiah).

Pasal 161

Setiap orang atau pemegang IUP Operasi Produksi atau IUPK Operasi Produksi yang menampung, memanfaatkan, melakukan pengolahan dan pemurnian, pengangkutan, penjualan mineral dan batubara yang bukan dari pemegang IUP, IUPK, atau izin sebagaimana dimaksud dalam Pasal 37, Pasal 40 ayat (3), Pasal 43 ayat (2), Pasal 48, Pasal 67 ayat (1), Pasal 74 ayat (1), Pasal 81 ayat (2), Pasal 103 ayat (2), Pasal104 ayat (3), atau Pasal 105 ayat (1) dipidana dengan pidana penjara paling lama 10 (sepuluh) tahun dan denda paling banyak Rp10.000.000.000,00 (sepuluh miliar rupiah).

Pasal 162

Setiap orang yang merintangi atau mengganggu kegiatan usaha pertambangan dari pemegang IUP atau IUPK yang telah memenuhi syarat-syarat sebagaimana dimaksud dalam Pasal 136 ayat (2) dipidana dengan pidana kurungan paling lama 1 (satu) tahun atau denda paling banyak Rp100.000.000,00 (seratus juta rupiah).

Pasal 163 
(1) Dalam hal tindak pidana sebagaimana dimaksud dalam bab ini dilakukan oleh suatu badan hukum, selain pidana penjara dan denda terhadap pengurusnya, pidana yang dapat dijatuhkan terhadap badan hukum tersebut berupa pidana denda dengan pemberatan ditambah $1 / 3$ (satu per tiga) kali dari ketentuan maksimum pidana denda yang dijatuhkan.

(2) Selain pidana denda sebagaimana dimaksud pada ayat (1), badan hukum dapat dijatuhi pidana tambahan berupa:

a. pencabutan izin usaha; dan/atau

b. pencabutan status badan hukum.

Pasal 164

Selain ketentuan sebagaimana dimaksud dalam Pasal 158, Pasal 159, Pasal 160, Pasal 161, dan Pasal 162 kepada pelaku tindak pidana dapat dikenai pidana tambahan berupa:

a. perampasan barang yang digunakan dalam melakukan tindak pidana;

b. perampasan keuntungan yang diperoleh dari tindak pidana; dan/atau

c. kewajiban membayar biaya yang timbul akibat tindak pidana.

Pasal 165

Setiap orang yang mengeluarkan IUP, IPR, atau IUPK yang bertentangan dengan Undang-Undang ini dan menyalahgunakan kewenangannya diberi sanksi pidana paling lama 2 (dua) tahun penjara dan denda paling banyak Rp200.000.000,00 (dua ratus juta rupiah).

Jika dilihat dalam pasal 158 sampai dengan pasal 165 maka ada dua sanksi yang dijatuhkan sanksi administratif dan/atau pidana. Karena kegiatan pertambangan bukan saja dilakukan oleh orang, namun terlibat didalamnya perusahan yang merupakan badan hukum atau korporasi.

2. Penjatuhan Sanksi Kasus Penambangan Batu Cinnabar di Maluku

Batu cinnabar setelah diolah maka yang dihasilkan adalah merkuri yang kemudian akan memiliki nilai jual. Namun dampak dari pengolahan yang tidak mempunyai amdal dan izin dari pemerintah tentu akan berdampak pada lingkungan. Bahaya racun merkuri bila menyebar ke lingkungan dapat membahayakan kesehatan masyarakat yang ada di sekitar wilayah tersebar merkuri. Elemen merkuri mempunyai dua sifat toksitas yang sangat berbahaya, yaitu elemen merkuri dapat menembus membran sel karena ia mempunyai sifat mudah sekali larut dalam lipida. Sehingga mudah sekali menembus barrier darah otak yang akhirnya terakumulasi di dalam otak, dan elemen merkuri sangat mudah sekali teroksidasi untuk membentuk Merkuri Oksida $(\mathrm{HgO})$ atau ion Merkuri $\left(\mathrm{Hg}^{2+}\right)$. Toksisitas kronik dari kedua elemen merkuri ini 
akan berpengaruh pada jenis organ yang berbeda yaitu saraf, otak dan ginjal. ${ }^{7}$

Pengolahan batu cinnabar di Maluku memiliki penambangan ilegal yang tidak mempunyai izin di Desa Luhu Kabupaten Seram Bagian Barat. Hal tersebut berdampak pada matinya hutan mangrove, dan penyakit bagi masyarakat. ${ }^{8}$ Sayangnya pidana yang dijatuhkan masih sangat lemah tidak sampai $1 / 2$ (satu per dua) dari ancaman hukuman yang ada. Padahal jika melihat fungsi preventif dari penjatuhan pidana adalah memberikan efek jera, seseorang yang telah melakukan tindak pidana akan takut melakukannya lagi. Beberapa kasus terakhir dilakukan penjatuhan pidana agar menimbulkan efek jera untuk orang yang melakukan. ${ }^{9}$

\section{Tabel II}

Amar Putusan Pengadilan, dan Ancaman Pidana Dalam Perkara Mineral dan Batu Bara

\begin{tabular}{|c|c|c|c|c|c|}
\hline No & Nomor Putusan & Ancaman & Amar Putusan & $\begin{array}{l}\text { Pasa } \\
\text { I }\end{array}$ & $\begin{array}{l}\text { Jumlah Barang } \\
\text { Bukti }\end{array}$ \\
\hline 1 & 48/Pid.Sus/2018/PN Amb & $\begin{array}{l}10 \text { (sepuluh) tahun } \\
\text { dan denda paling } \\
\text { banyak } \\
\text { Rp10.000.000.000 } \\
\text { (sepuluh miliar } \\
\text { rupiah). }\end{array}$ & $\begin{array}{l}8 \quad \text { (delapan) } \\
\text { bulan dan } \\
\text { denda sebesar: } \\
\text { Rp. } \\
500.000 .000 .-\end{array}$ & 161 & $\begin{array}{l}269 \text { (dua ratus } \\
\text { enam puluh } \\
\text { Sembilan) Karung } \\
\text { berisi material } \\
\text { tambang } \\
\text { jenis cinnabar }\end{array}$ \\
\hline 2 & 241/Pid.Sus/2018/PN Amb & $\begin{array}{l}10 \text { (sepuluh) tahun } \\
\text { dan denda paling } \\
\text { banyak } \\
\text { Rp10.000.000.000 } \\
\text { (sepuluh miliar } \\
\text { rupiah). }\end{array}$ & $\begin{array}{l}\text { pidana penjara } \\
\text { selama } 1 \text { (satu) } \\
\text { tahun } 2 \text { (dua) } \\
\text { bulan dan } \\
\text { denda sebesar } \\
\text { Rp.1.000.000- } \\
\text { (satu juta } \\
\text { rupiah) }\end{array}$ & 161 & $\begin{array}{l}130 \text { (seratus tiga } \\
\text { puluh) karung yang } \\
\text { berisikan serpihan } \\
\text { batu yang diduga } \\
\text { batu cinnabar; }\end{array}$ \\
\hline 3 & 221/Pid.Sus/2018/PN Amb & $\begin{array}{l}10 \text { (sepuluh) tahun } \\
\text { dan denda paling } \\
\text { banyak } \\
\text { Rp10.000.000.000 } \\
\text { (sepuluh miliar } \\
\text { rupiah). }\end{array}$ & $\begin{array}{l}2 \text { (dua) tahun } \\
\text { dan } \\
\text { menjatuhkan } \\
\text { denda kepada } \\
\text { terdakwa } \\
\text { sebesar: } \\
\text { Rp.1.000.000.0 } \\
00,- \text { (satu milyar } \\
\text { rupiah) }\end{array}$ & 161 & $\begin{array}{l}3 \text { (tiga) buah } \\
\text { jerigen bekas Merk } \\
\text { Bimoli ukuran } 5 \\
\text { liter berisi } \\
\text { Mercury/air raksa } \\
\text { dengan berat total } \\
68 \text { (enam puluh } \\
\text { delapan kilogram); }\end{array}$ \\
\hline
\end{tabular}

${ }^{7}$ M. Choirul Hadi, Bahaya Merkuri di Lingkungan Kita, Jurnal Skala Husada Volume 10 Nomor 2 2013, hal 175-183

${ }^{8}$ Denar A. Surahmo, Bentuk dan Dampak Aktifitas Penambangan Batu Cinnabar Terhadap Ekosistem Pantai di Pesisir Pantai Batu Kapal Di Negeri Luhu Kecamatan Huamual Kabupaten Seram Bagian Barat, IAIN Ambon. 2018 hal 29

${ }^{9}$ I Ketut Merta, Efek Jera, Pemiskinan Koruptor, dan Sanksi Pidana, Udayan Press, 2018 hal 3 


\begin{tabular}{|c|c|c|c|c|c|}
\hline 4 & 242/Pid.Sus/2018/PN Amb. & $\begin{array}{l}10 \text { (sepuluh) tahun } \\
\text { dan denda paling } \\
\text { banyak } \\
\text { Rp10.000.000.000- } \\
\text { (sepuluh miliar } \\
\text { rupiah). }\end{array}$ & 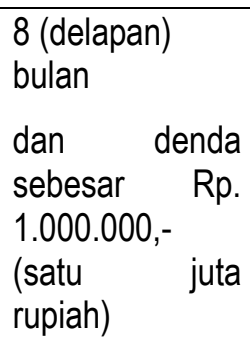 & 161 & $\begin{array}{l}130 \text { (seratus tiga } \\
\text { puluh) karung yang } \\
\text { berisikan serpihan } \\
\text { batu yang } \\
\text { batu Cinnabar }\end{array}$ \\
\hline 5 & 244/Pid.Sus/2018/PN Amb & $\begin{array}{l}10 \text { (sepuluh) tahun } \\
\text { dan denda paling } \\
\text { banyak } \\
\text { Rp10.000.000.000.- } \\
\text { (sepuluh miliar } \\
\text { rupiah). }\end{array}$ & $\begin{array}{l}8 \text { (delapan) } \\
\text { bulan dan } \\
\text { denda sebesar } \\
\text { Rp. 1.000.000,- } \\
\text { (satu juta } \\
\text { rupiah) }\end{array}$ & 161 & $\begin{array}{l}130 \text { (seratus tiga } \\
\text { puluh) karung yang } \\
\text { berisikan serpihan } \\
\text { batu yang } \\
\text { batu Cinnabar; }\end{array}$ \\
\hline 6 & 47/Pid.Sus/2018/PN Amb & $\begin{array}{l}10 \text { (sepuluh) tahun } \\
\text { dan denda paling } \\
\text { banyak Rp } \\
10.000 .000 .000 \\
\text { (sepuluh miliar } \\
\text { rupiah). }\end{array}$ & 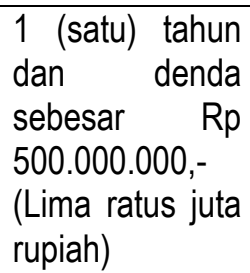 & 161 & 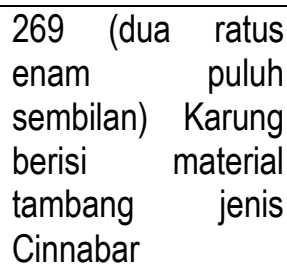 \\
\hline 7 & 304/Pid.Sus/2018/PN Amb & $\begin{array}{l}10 \text { (sepuluh) tahun } \\
\text { dan denda paling } \\
\text { banyak } \\
\text { Rp10.000.000.000. } \\
\text { (sepuluh miliar } \\
\text { rupiah). }\end{array}$ & $\begin{array}{l}2 \text { (dua) } \\
\text { (enam) bulan } 6 \\
\text { dan } \\
\text { sebesar Rpenda } \\
\text { 100.000.000,- } \\
\text { (seratus juta } \\
\text { rupiah) }\end{array}$ & 161 & $\begin{array}{l}3 \text { gen plastik } \\
\text { ukuran } 5 \text { liter warna } \\
\text { putih berisikan air } \\
\text { perak } / \text { merkuri } \\
\text { dicampur dengan } \\
\text { air berat dengan } \\
\text { berat masing- } \\
\text { masing }+28 \mathrm{~kg} .+ \\
28 \mathrm{~kg} . \pm 8 \mathrm{~kg} \text {. }\end{array}$ \\
\hline 8 & 187/Pid.Sus/2019/PN Amb & $\begin{array}{l}10 \text { (sepuluh) tahun } \\
\text { dan denda paling } \\
\text { banyak } \\
\text { Rp10.000.000.000. } \\
\text { (sepuluh miliar } \\
\text { rupiah). }\end{array}$ & $\begin{array}{lr}\text { pidana } & \text { penjara } \\
\text { selama } & 4 \\
\text { (empat) } & \text { bulan } \\
\text { dan } & \text { denda } \\
\text { sebesar } & \text { Rp- RP. } \\
500.000,- & \text { (lima } \\
\text { ratus } & \text { ribu } \\
\text { rupiah) } & \end{array}$ & 161 & $\begin{array}{l}4 \text { (empat) buah tas } \\
\text { koper warna ungu } \\
\text { dan warna coklat } \\
\text { merk elle; } \\
\text { b. } 8 \text { (delapan) buah } \\
\text { botol oli ukuran } 1 \\
\text { (satu) liter yang } \\
\text { berisi Mercuri } \\
\text { dengan berat } \\
\text { kurang lebih } 127 \\
\text { Kg }\end{array}$ \\
\hline
\end{tabular}

Melihat daftar putusan-putusan pengadilan di atas, maka akan diambil beberapa analisis, yaitu:

a. Puluhan sampai ratusan rampasan batu cinnabar maupun bahan yang sudah menjadi merkuri diserahkan ke Kementrian Lingkungan Hidup.

b. Penjatuhan Pidana kepada pelaku penambang ilegal batu cinnabar masih sangat 
rendah, tidak sampai $1 \frac{1}{2}$ (satu per dua) dari ancaman 10 tahun dalam Pasal 161 Undang-Undang Nomor 4 Tahun 2009, tentang Pertambangan Mineral dan Batu Bara.

\section{KESIMPULAN}

Hasil penelitian dapat disimpulkan bahwa penjatuhan pidana yang dapat menimbulkan efek jera bagi pelaku dan calon pelaku tindak pidana mineral dan batu bara, namum pada kenyataannya hukuman pidana yang dijatuhkan dalam perkara mineral dan batu bara masih rendah. Padahal ancaman 10 tahun penjara untuk pelaku, karena akibat dari penambangan yang tidak ada analisis dampak lingkungan berakibat pada lingkungan di Desa Luhu Kabupaten Seram Barat Provinsi Maluku mengalami rusak mangrove dan penyakit pada manusia.

\section{REFERENSI}

Aji, A.M.; Yunus, N.R. Basic Theory of Law and Justice, Jakarta: Jurisprudence Institute, 2018.

Barda Nawawi Arief, Bunga Rampai Kebijakan Hukum Pidana, Kencana Prenada, Bandung, 2005

Coles, C. A. Mercury Cyanide Contamination of Groundwater from Gold Mining and Prospects for Removal. Sea to Sky Geotechnique. 2006

I Ketut Merta, Efek Jera, Pemiskinan Koruptor, dan Sanksi Pidana, Udayan Press, 2018.

Morisan. Negara Hukum, Rajawali Press, Jakarta, 2015.

Maggalatung, A.S.; Aji, A.M.; Yunus, N.R. How The Law Works, Jakarta: Jurisprudence Institute, 2014.

Nandang Sudrajat, Teori dan Praktik Pertambangan Indonesia Menurut Hukum, Pustaka Yustisia, Jakarta, 2010.

Philipus M. Hadjon, Perlindungan Hukum Bagi Rakyat di Indonesia, Sebuah Studi tentang Prinsip-Prinsipnya dan Penanganannya oleh Pengadilan Dalam Lingkungan Peradilan Umum dan Pembentukan Peradilan Administrasi, Edisi Khusus, Penerbit Peradaban, Cet. Pertama, 2007.

Tolib Setiady, Pokok-Pokok Hukum Penintesier Indonesia, Alfabeta, 2010.

Denar A. Surahmo, Bentuk dan Dampak Aktifitas Penambangan Batu Cinnabar Terhadap Ekosistem Pantai di Pesisir Pantai Batu Kapal Di Negeri Luhu Kecamatan Huamual Kabupaten Seram Bagian Barat, IAIN Ambon. 2018

E. Leasa, “Eksistensi Ancaman Pidana Mati Dalam Tindak Pidana Korupsi Pada Masa Pandemik Covid-19", Jurnal Belo, vol. 6, no. 1, pp. 73-88, 2020. 
M. Choirul Hadi, Bahaya Merkuri di Lingkungan Kita, Jurnal Skala Husada Volume 10 Nomor 22013

Rosita Rizki Maulidiah dan Suprapto, Pemisahan Merkuri dari Batuan Cinnabar dengan Asam dan Campuran Asam-Kalium Iodida, JURNAL SAINS DAN SENI ITS Vol. 4, No.2. 2018

Ubwarin, E., \& Corputty, P. (2020). Pertangungjawaban Pidana Dalam Keadaan Darurat Bencana Covid-19. Mizan: Jurnal Ilmu Hukum, Volume 9 Nomor 1. Hal 6. DOI : https://doi.org/10.32503/mizan.v9i1.1043

Yunus, N.R.; Anggraeni, RR Dewi.; Rezki, Annissa. "The Application of Legal Policy Theory and its relationship with Rechtsidee Theory to realize Welfare State," 'Adalah, Volume 3, No. 1 (2019) 